\title{
Los nueve años del TLC Perú - China. Su negociación y sus resultados
}

\author{
Julio Chan ${ }^{*}$
}

\begin{abstract}
RESUMEN
El Acuerdo de libre comercio entre el Perú y la China tiene como características un proceso de larga gestación y un proceso de breve negociación. Las concesiones arancelarias intercambiadas permiten que la inmensa mayoría de los potenciales productos de exportación peruanos puedan tener acceso a beneficios arancelarios. Por otro lado, prácticamente todos los productos peruanos sensibles a la competencia china fueron excluidos del proceso de desgravación tarifaria o se incluyeron a plazos de hasta diecisiete años de reducciones arancelarias. Luego de nueve años de vigencia del acuerdo, se concluye que este ha sido beneficioso para el Perú sin dejar de mantener la característica esencial de la estructura de su comercio: el ser interindustrial.

Palabras clave: Perú, China, Mincetur, Acuerdo/Tratado de Libre comercio, negociaciones comerciales internacionales, comercio exterior, exportaciones, exportaciones tradicionales, exportaciones no tradicionales, importaciones, bienes de consumo, insumos y productos intermedios, bienes de capital, balanza comercial, intercambio comercial.
\end{abstract}

\section{Nine Years of FTA Peru - China: its negotiation and its results}

\section{Abstract}

The Free Trade Agreement between Peru and China has as characteristics a long process of gestation and a brief process of negotiation. Tariffs benefits agreed allow for the great majority of potential Peruvian exports products to have access to tariffs reductions. On the other hand, almost all Peruvian products sensitive to Chinese competition were excluded from the tariff reduction process or were included with up to 17 years of tariffs reductions. After nine years of entering into force, it is concluded that the agreement has been beneficial for Peru, notwithstanding the essential characteristic of its trade structure: that of being interindustrial.

* Coordinador general del Foro de Cooperación Económica Asia-Pacífico del Ministerio de Comercio Exterior y Turismo del Perú (Mincetur). PhD en Ciencia Política, economista. Correo electrónico: jjchs@yahoo.com

La valiosa contribución del seńor Walter Ibarra ha sido fundamental para que este trabajo tenga sustancialmente una mejor presentación. El autor queda profundamente agradecido y reconocido por la calidad de su trabajo.

iD https://orcid.org/ 0000-0002-5750-9794 
Keywords: Peru, China, Mincetur, free trade agreement/treaty, international trade negotiations, foreign trade, exports, traditional exports, non-traditional exports, imports, consumption goods, inputs and intermediate goods, capital goods, trade balance, total trade.

El Acuerdo de libre comercio entre el Perú y la China ha cumplido en marzo de 2019, nueve años de vigencia. Como cualquier negociación de preferencias comerciales, esta se lleva a cabo cuando el interés para ello coincide con otras circunstancias, sobre todo la decisión política. El caso del tratado de libre comercio (TLC) con la China no fue una excepción. Además del interés permanente del Perú de negociarlo, fue necesaria la circunstancia adecuada para que el gobierno chino coincidiese con el objetivo peruano. La visita de Estado del presidente chino al Perú, en el marco de la Reunión de los Líderes de las Economías del Foro de Cooperación Económica del Asia-Pacífico (APEC) en Lima, en noviembre de 2008, propició que dichas negociaciones se realizaran durante dicho año, haciendo que este acuerdo fuese el que se negocie en el tiempo más breve que otros.

El largo proceso de negociación para la negociación de este acuerdo es lo que lo caracteriza y singulariza. En el presente trabajo se dan a conocer algunos detalles de este largo proceso, así como se resume el rápido proceso de la negociación del acuerdo en sí. Asimismo, se presentan los aspectos más importantes del convenio en relación al tema que continúa siendo el más relevante en todo tratado de libre comercio: el acceso a mercado de las mercancías. Se finaliza con un análisis macro de los resultados del intercambio comercial.

\section{Negociando la negociación del acuerdo de libre comercio entre el Perú y la China $^{1}$}

En noviembre de 2004, el presidente Alejandro Toledo anunció a su colega de Beijing, $\mathrm{Hu}$ Jintao, que el Perú reconocía a la China como «economía de mercado»².

\footnotetext{
1 Esta parte se basa en las reminiscencias del autor, quien fue partícipe de algunas de las situaciones reseñadas. Sin embargo, es fundamental dejar muy en claro, que estos recuerdos son los del autor, los cuales podrían no estar fielmente ajustados a la realidad, ni coincidir con las memorias de otros participantes en este proceso, varios de los cuales tuvieron papeles y acciones mucho más relevantes y decisivas.

2 Durante las negociones para la accesión de la China a la Organización Mundial del Comercio (OMC), se acordó que luego de quince ańos de su ingreso a la OMC (diciembre 2016), los miembros tratarían a la China como economía de mercado. Sin embargo, eso no fue óbice para que, en el ínterin, dicho miembro se embarcara en una campaña intensa de lograr su reconocimiento anticipado como tal.

En la actualidad, cumplido ya el plazo, estamos en la paradoja de que muchos de los miembros de la OMC no cumplen con lo acordado. En esta negativa, sobresalen por su importancia, EE.UU., la Unión Europea, Japón, entre otros.
} 
Esta inesperada declaración unilateral y no prevista por la contraparte causó una muy grata reacción por parte del presidente Hu y de su delegación ${ }^{3}$.

En Lima, sin embargo, esta acción causó sorpresa y consternación entre los funcionarios del Ministerio de Comercio Exterior y Turismo (Mincetur) y de sus pares del viceministerio de Industria del Ministerio de la Producción. Estas reacciones se debieron a que, por un lado, el reconocimiento fue considerado prematuro. Pero más importante aún, porque, luego se confirmó, que el reconocimiento se otorgó sin mediar algo a cambio.

Si bien era muy claro para los funcionarios encargados de las relaciones con la China, que tarde o temprano ese reconocimiento debería ser otorgado, hacerlo en noviembre de 2004, solo después de Chile ${ }^{4}$ era apresurado.

Los funcionarios tenían como punto de vista de que este reconocimiento debió haberse anunciado luego que más partes contratantes de la OMC lo hubiesen hecho. Y más aún, que el gobierno peruano hubiese negociado con el chino para obtener algunas concesiones tales como permisos sanitarios y fitosanitarios para el acceso al mercado chino de productos peruanos, inversiones en áreas que el Perú tenía interés en promover, cooperación económica y técnica, etc.

Dadas las circunstancias, en posteriores reuniones entre funcionarios peruanos de diversas reparticiones estatales relevantes y funcionarios de la embajada China y de su oficina comercial, no se pudo superar la situación. Ni los chinos lograban avanzar en la formalización oficial del reconocimiento de su país como economía de mercado, ni el Perú obtenía respuestas favorables hacia la obtención de algunas concesiones. Los primeros consideraban que como nada se había solicitado a cambio en la reunión de noviembre de 2004, su gobierno no estaba ni en la necesidad ni en la obligación de ofrecer algo a cambio. Por el lado de los peruanos, la posición, no alentada pero tampoco desautorizada por sus autoridades, fue que algo se tenía que obtener a cambio del reconocimiento.

Conforme pasaba el tiempo (2005-2006), las posiciones se fueron inflexibilizando. Por el lado de los funcionarios peruanos se barajaron alternativas que formaron un paquete de requerimientos. Entre estos estaba el financiamiento de un centro para la mejora de la calidad y la producción textil y otro para el calzado, un acuerdo de

\footnotetext{
3 Este reconocimiento se realizó en el transcurso de la reunión de ambos mandatarios en el marco de sus participaciones en la Reunión Anual de los Líderes de las Economías del foro de Cooperación Económica Asia-Pacífico, APEC (AELM - Annual Economic Leaders Meeting) llevada a cabo en Santiago de Chile.

4 El primer país del mundo en hacerlo. Este reconocimiento fue realizado pocos días antes de la reunión entre el Perú y la China. Ello dio paso a la negociación del TLC entre ambos países. Así, Chile fue el primer país de la región en tener un acuerdo bilateral de comercio con la China.
} 
intercambio de información de precios domésticos de productos importados por la otra parte, inversiones para la mejora de la productividad de la cadena textil y del calzado, inversiones para la producción de productos agroindustriales de interés chino para consumo de su mercado, así como en la infraestructura necesaria para transportar eficientemente dichos productos de los lugares de sus producciones al mercado local del destino final. El pedido máximo fue que el gobierno chino accediera a negociar un acuerdo de libre comercio con el Perú.

Los chinos insistieron persistentemente que, para cualquier ofrecimiento unilateral de su gobierno, era condición sine qua non el reconocimiento oficial. Sin embargo, repentinamente los funcionarios chinos en el Perú dejaron de insistir en un documento legal de reconocimiento. Luego de un periodo de calma por el lado peruano, empezó la preocupación del cambio repentino del accionar chino. Con el paso del tiempo se despejó la incógnita.

En algún momento, consultando un funcionario peruano, de manera informal, a su colega chino de este cambio de actitud por su parte y por parte de sus colegas connacionales en la capital china, su respuesta no se dejó esperar. Para ellos y para su gobierno era más que suficiente la palabra dada por el presidente del Perú para darse por satisfechos y seguros del reconocimiento peruano a la China como economía de mercado.

Esta verdad de Perogrullo, luego de la sorpresa inicial entre los funcionarios peruanos, fue aquilatada en toda su dimensión. Pesó en ello el proverbial y conocido mayor valor que se da a la palabra sobre el documento en la cultura china y que, en el caso peruano, es el presidente de la república quien conduce la política exterior del país. Resultaba obvio que la palabra dada y empeñada por el presidente es el nivel más alto de compromiso del gobierno del Perú con otro gobierno. Sin embargo, si esta acción no está acompañada de una consiguiente formulación reglamentaria necesaria, esta no puede ser implementada por parte de la maquinaria gubernamental nacional'5

Con esta situación paradójica para los funcionarios peruanos se llegó a fines de julio de 2006, y con ello asume la presidencia Alan García. En el nuevo gabinete, Mercedes Aráoz era designada como ministra de Comercio Exterior y Turismo.

\footnotetext{
5 Esta situación fue similar a la de la Argentina que por un Memorándum de Entendimiento firmado por los presidentes Néstor Kirchner y Hu Jintao, el 17 de noviembre de 2004, reconoció a la China como economía de mercado. En este caso se argumentó que «jurídicamente no se trata de un compromiso legal y explícito hacia el reconocimiento [...] a China, ya que requiere de su implementación doméstica para poder ser efectivo. Sin embargo, Argentina nunca ha ratificado dicho Memorando de Entendimiento y, por tanto, nunca fue implementado el compromiso [...]» (Bianco, 2016, p. 21). Hasta el momento, abril de 2019, la Argentina carece de un acuerdo de libre comercio con la República Popular China.
} 
Las nuevas autoridades estaban decididas en seguir profundizando más rápidamente las relaciones con el Este del Asia, primero con la China, y luego con el Japón y con Corea. Para ello, a los negociadores del Mincetur se les encargó la tarea de hallar una forma de lograr que la China acepte negociar un acuerdo de libre comercio.

Los intercambios de puntos de vista entre los funcionarios peruanos, primero con sus contrapartes de la embajada y en la oficina comercial de la China en el Perú y luego con funcionarios del Ministerio de Comercio de la China (Ministry of Foreign Trade - Mofcom), dieron lugar a un intenso proceso de negociaciones. Ello allanó el camino y la fórmula, así como el procedimiento por el cual el gobierno chino aceptaría la solicitud del gobierno peruano de negociar un acuerdo bilateral de comercio concomitante al reconocimiento gubernamental peruano de la China como economía de mercado.

Ambas partes coincidieron que el momento y lugar más adecuado sería durante la reunión de ministros de Comercio Exterior y de Relaciones Exteriores de APEC, que se llevaría a cabo en noviembre de 2006 en Hanói, Vietnam ${ }^{6}$. Para ello se realizaría una reunión entre los ministros del Mincetur y del Mofcom. Se concordó que en ella la ministra Aráoz entregara un oficio en el cual se propusiera la negociación de un acuerdo de libre comercio entre ambas naciones y se reconociese a la China como economía de mercado. También el oficio coincidía con la solicitud china de realizar un estudio conjunto para determinar previamente la viabilidad del acuerdo de libre comercio.

El 18 de noviembre de 2016, en Hanói, en el marco de la semana que culminó con las reuniones de los líderes de las economías de APEC, se llevó a cabo la reunión entre la ministra Mercedes Aráoz, con el ministro chino de Comercio de la República Popular China, Bo Xilai.

Luego de los intercambios preliminares y protocolares de estilo, la ministra Aráoz hizo entrega del oficio conteniendo lo previamente pactado haciendo simultáneamente un resumen del mismo y sobre todo enfatizando en la negociación del acuerdo de libre comercio. El ministro Bo recibió el oficio con las formalidades del caso y, sin intentar mirarlo, lo entregó rápidamente a uno de sus viceministros (el de la izquierda, el de menor jerarquía, lo que es captado por el lado peruano como una señal poco auspiciosa).

La ministra Aráoz rompió el silencio al comentar sobre los aspectos comunes entre el Perú y la China. Así, aludió a que ambos han sido cuna de culturas milenarias

\footnotetext{
6 Esta es la Reunión Anual de Ministros (Annual Ministerial Meeting - AMM) que en el Perú se le denomina extraoficialmente, y por claridad Reunión Anual Ministerial Conjunta de Ministros de Relaciones Exteriores y de Ministros de Comercio (Chan, 2008, p. 13).
} 
que han sido ejemplo y modelo en sus zonas de influencia, con un pasado glorioso y un futuro prometedor, y que están cada vez más entrelazados, para luego reiterar brevemente el contenido del oficio. El ministro Bo recibió apreciativamente estos comentarios culturales y celebró el gran nivel en que se hallaban las relaciones bilaterales. Agradeció, también, el reconocimiento peruano a la China como economía de mercado mencionado por la ministra Aráoz.

Ella, en su intervención siguiente, se refirió a los profundos lazos bilaterales gubernamentales que vienen del siglo XIX. Así, expresó que el Perú fue el primer país latinoamericano en establecer relaciones diplomáticas con el Imperio chino ${ }^{7}$ y ser el tercero en la región ${ }^{8}$ en reconocer a la República Popular China como el gobierno legítimo de la China9. Finalizó reiterando el interés gubernamental peruano de continuar profundizando las relaciones bilaterales ${ }^{10}$, en especial las comerciales. El ministro Bo respondió agradeciendo estos tempranos reconocimientos diplomáticos del gobierno peruano y mencionó que el lado chino podría considerar llevar a cabo el estudio conjunto. Esta declaración del ministro Bo produjo una profunda y positiva sorpresa en los delegados peruanos. Para todos ellos, esto significaba que la negociación del acuerdo comercial iba a llevarse a cabo.

El agradecimiento peruano, a través de la ministra Aráoz, no se dejó esperar y con su concurrencia a lo sugerido por el ministro Bo, ella propuso que el estudio conjunto se llevara a cabo a la brevedad. Aprovechó también la ministra en resaltar las importantes relaciones sociales y culturales entre ambos países. Así mencionó que la temprana migración de chinos al Perú, a mediados del siglo XIX, había logrado que aspectos importantes de la cultura china se fusionen en la cultura peruana. Citó como ejemplos la existencia de palabras en el hablar del peruano que son propias de la gastronomía china, la existencia única en el mundo de los «chifas» en el Perú, para referirse a los restaurantes de comida china, así como la comunidad china y sus descendientes, que es hasta ahora la más numerosa de América Latina.

El ministro Bo acogió apreciativamente estos detalles culturales y continuó sorprendiendo a la delegación peruana al anunciar su concurso a la propuesta peruana de llevar a cabo el estudio lo antes posible, señalando su posible inicio en enero de 2007 y que para ello él designaría a su equipo a la brevedad solicitando a la parte peruana

\footnotetext{
7 «[...] el Tratado de Amistad, Comercio y Navegación de [sic] 26 de junio de 1874 [...] establecía el intercambio de Agentes Diplomáticos [...] [que] gozarían de los privilegios e inmunidades concedidos por los usos internacionales» (García-Corrochano y Tang, 2011, pp. 60-61).

8 Después de Cuba (1960) y Chile (1970).

9 Por acta suscrita el 2 de noviembre de 1971 en Ottawa por los respectivos representantes diplomáticos ante Canadá (García-Corrochano y Tang, 2011, p. 119).

${ }^{10}$ Una breve pero integral revisión de estas relaciones se encuentra en: Novak y Namihas 2016.
} 
hacer lo mismo. Adicionalmente, mencionó que a mediados de 2007 se podría finalizar y presentar dicho estudio, y que ello a su vez permitiría dar a lugar a un pronto inicio de las negociaciones del acuerdo comercial en la segunda mitad de dicho año y tal vez finalizarlo en noviembre de 2008, con motivo de la cumbre APEC a llevarse a cabo en el Perú.

Ante estos inesperados anuncios del ministro chino, su par peruano rápidamente asintió e impartió las instrucciones del caso a los funcionarios que la acompañaban. No es necesario mencionar que dicha reunión, llena de sorpresas positivas, finalizó dejando a la delegación peruana con sentimientos de profunda satisfacción y de haber logrado todo lo que se esperaba, pero en plazos más prontos de los previstos.

Habría ahora que tratar de responder a la pregunta obvia sobre la razón de este avance tan sustancial en la reunión en Hanói. Por un lado, el pragmatismo chino debió haber jugado un importante papel. Había intereses comerciales y financieros por solidificar en la relación peruano-china. El rápido crecimiento económico que ya estaba experimentando la China requería de accesos seguros no solo a materias primas, en especial el cobre; sino también a los productos agropecuarios para el consumo de su creciente clase media (Morales, 2017). El acuerdo permitiría asegurar estos abastecimientos, así como las inversiones chinas en los sectores de producción peruanos importantes para los chinos.

Por otro lado, un aspecto político-diplomático. El Perú ya estaba previsto de presidir el foro APEC en 2008 que, como es costumbre, culminó con la reunión de los veintiún líderes de las economías miembro. En el marco de estas cumbres, el presidente chino aprovechó para realizar una visita del más alto nivel al país, durante el cual el gobierno chino firmó una serie de compromisos bilaterales, incluyendo algunos de gran trascendencia como lo era la firma de un acuerdo de comercio bilateral. Fijada la fecha para el logro del objetivo, noviembre de 2008; quedaba entonces tiempo limitado para realizar el estudio conjunto y llevar a cabo las negociaciones mismas. Adicionalmente, el gobierno chino finalmente logró que el gobierno peruano de manera formal, por parte de la autoridad encargada de los temas de la OMC, reconociera su condición de economía de mercado.

Por el lado peruano, vale la pena reiterar, un TLC con la China respondía al avance de objetivos de largo plazo, así como a logros más inmediatos. Entre los primeros hay que seńalar la política de Estado de libre comercio negociado con la finalidad de hacer del comercio exterior un motor del crecimiento y del bienestar nacional. Para ello, es esencial una relación más estrecha tanto comercial como de otras índoles, con el Asia-Pacífico (la región que desde hace más de cincuenta años es la más dinámica del mundo en cuanto a crecimiento económico y también en cuanto a desarrollo). 
El objetivo de largo plazo es que el Perú sea el puente entre Asia del Este y América del Sur para su comercio de bienes y de servicios. En este marco, un TLC con la China, el mercado más dinámico del mundo, era un elemento fundamental para avanzar en los objetivos mencionados. Ello serviría, en el corto plazo, para aumentar nuestras exportaciones, en especial las no tradicionales; lograr importar productos necesarios a un precio más bajo y fomentar las inversiones chinas en el país.

\section{La negociación del acuerdo del libre comercio Perú-China}

Rápidamente, el Mincetur aceleró el trabajo interno y de coordinación con su contraparte china para definir los términos de referencia del estudio y las formalidades para llevarlo a cabo. Se acordó, por ejemplo, que el estudio fuese llevado a cabo por las áreas de estudios económicos del Mincetur y del Mofcom y que el mismo sea un único documento conjunto. Asimismo, se definieron las fechas para intercambio de la información, entrega de los avances y los comentarios a los mismos, así como para la finalización del mismo.

En febrero de 2007, ambos ministros acordaron la realización de un estudio conjunto de factibilidad. En el anuncio de esta decisión se dio a conocer que el fin del estudio era «analizar las tendencias recientes del comercio bilateral y las inversiones; identificar posibles barreras que afecten al comercio actual de bienes y servicios; estimar el impacto de la liberalización arancelaria en ambos países y elaborar una serie de recomendaciones para profundizar las relaciones económicas bilaterales» (Mincetur, s/f $\mathrm{a}$ ).

El estudio comprendió la revisión de las políticas económicas y comerciales así como de las relaciones comerciales bilaterales. También se realizó un análisis de las sensibilidades del impacto de las negociaciones. Este análisis llevó a la determinación de que era necesario otorgar tratamientos especiales a productos sensibles para el Perú, en especial los de los sectores textil, confecciones, calzado y metalmecánico. Sin embargo, la principal conclusión del estudio fue que el TLC Perú-China sería beneficioso para las partes.

En agosto de 2007, se anunció la finalización del estudio conjunto ${ }^{11}$. Posteriormente, en el marco de la cumbre de líderes de las economías de APEC, en Sídney (Australia), el 7 de setiembre, los presidentes Alan García y Hu Jintao, se reunieron de manera bilateral. En ese encuentro ambos anunciaron el lanzamiento oficial de las negociaciones comerciales entre el Perú y la China. En dicha reunión, este anuncio fue

\footnotetext{
${ }^{11}$ El texto completo se encuentra en: Mincetur, s/f b.
} 
formalizado por los ministros de Comercio de ambos países, con la subscripción del Memorándum de Entendimiento sobre el Fortalecimiento de las Relaciones Económicas y Comerciales entre el Ministerio de Comercio Exterior y Turismo de la República del Perú y el Ministerio de Comercio de la República Popular China ${ }^{12}$.

Paralelamente al estudio, se organizó un equipo de trabajo, sobre la base de la planta de funcionarios negociadores del Mincetur. El mismo, dirigido por los responsables de cada área, empezó a analizar, en estrecha coordinación con las instituciones públicas relevantes, la situación peruana y la china en los temas a incluirse en el TLC. Ello permitió estar preparados para la reunión técnica de noviembre de 2007 en Beijing. En ella, funcionarios se pusieron de acuerdo con los asuntos a incluir en el acuerdo y trataron los asuntos generales y procedimentales relacionados a la negociación comercial.

Este acuerdo a negociar sería el segundo del Perú con un país del Asia, y también era el segundo negociado por la China con un país latinoamericano ${ }^{13}$. Asimismo, acordaron un cronograma tentativo de rondas de negociaciones y aspectos formales.

Las negociaciones se dividieron en las siguientes mesas de trabajo:

- Acceso a mercados

- Reglas de origen

- Defensa comercial

- Servicios

- Inversiones

- Medidas sanitarias y fitosanitarias

- Obstáculos técnicos al comercio

- Solución de controversias

- Procedimientos aduaneros

- Asuntos institucionales

- Propiedad intelectual

- Cooperación

\footnotetext{
${ }^{12}$ Véase el texto en: Congreso, $\mathrm{s} / \mathrm{f}$.

${ }^{13}$ En el caso peruano, desde 2004 se estaba negociando un TLC con Tailandia, cuyo acuerdo parcial fue firmado en Busan (Corea del Sur), en noviembre de 2005, aprovechando la presencia de ambos presidentes en la reunión de Líderes de APEC de dicho año. En el caso de la China, esta nación ya tenía un acuerdo comercial con Chile que entró en vigencia en octubre de 2006, pero solo contempla el comercio de mercancías.
} 
Entre enero y octubre de 2008 se llevaron a cabo las seis rondas de negociaciones que fueron necesarias para llegar al acuerdo (véase cuadro 1). La primera de las cuales se realizó en Lima y la última en Beijing ${ }^{14}$.

Cuadro 1. Rondas de negociación del TLC Perú - China

\begin{tabular}{cll}
\hline Ronda & \multicolumn{1}{c}{ Fecha } & \multicolumn{1}{c}{ Lugar } \\
\hline I & 20-23 de enero de 2008 & Lima - Perú \\
II & 3-7 de marzo de 2008 & Beijing - China \\
III & 12-16 de mayo de 2008 & Beijing - China \\
IV & 28 de junio - 3 de julio de 2008 & Lima - Perú \\
V & 25-30 de agosto de 2008 & Lima - Perú \\
VI & 13-21 de octubre de 2008 & Beijing - China \\
\hline
\end{tabular}

Fuente: Mincetur, s/f a.

Luego de la ronda final, se inició de inmediato la revisión de los textos de manera transversal para estandarizar los formatos y estilos de denominación de los diversos términos técnicos, así como los aspectos formales y tipográficos de modo que se minimicen las ambigüedades y se maximice la claridad del texto final. También, como es costumbre, se intercambiaron puntos de vista para corregir errores y omisiones debidos a la presión y el fragor de las negociaciones.

En el ámbito doméstico, para los actores relevantes ${ }^{15}$, el anuncio de los positivos resultados de la reunión bilateral en Hanói, en noviembre de 2006, causaron como era de esperarse, reacciones encontradas. Las preocupaciones más importantes eran las sensibilidades de los productores nacionales frente a la posible mayor competencia china en los rubros textiles y calzados ${ }^{16}$. Esta aprensión manufacturera también era compartida, hasta cierto punto, por la población en general: la invasión masiva de productos chinos, más baratos que otros, aunque en algunas ocasiones de calidad dudosa. En todo caso, el Perú se abocaba a negociar su segundo acuerdo comercial más importante, después del negociado con Estados Unidos. Ello, evidentemente, no solo concitó el interés

\footnotetext{
${ }^{14} \mathrm{El}$ informe final se puede hallar en Mincetur $\mathrm{s} / \mathrm{f}$ a.

15 En este caso, además de los gremios empresariales manufactureros más importantes, también fueron actores relevantes los nuevos gremios de productores agroindustriales, así como sindicatos, la academia y organizaciones no gubernamentales. Y, en su momento, lo fueron los miembros del Congreso, en especial los de la Comisión de Comercio Exterior y Turismo.

${ }^{16}$ En estas áreas, el papel del Ministerio de Agricultura y del Viceministerio de Industria fueron muy relevantes en definir y precisar las posiciones negociadoras peruanas.
} 
sino también la preocupación y los retos, en algunos casos, las oportunidades y beneficios en muchos otros de los diversos sectores y estamentos de la población, tanto en Lima como en provincias. Adicionalmente, en sus momentos, el interés y la cobertura mediática fueron intensos, especialmente luego de la última ronda, con motivo de la suscripción del acuerdo, así como al momento de su puesta en vigencia.

El Mincetur, para atender a estas preocupaciones domésticas, puso en práctica los procesos, mecanismos y medios de transparencia y comunicación ya desarrollados y exitosamente aplicados durante las negociaciones del TLC con Estados Unidos (Chan, 2018, pp. 205-212). Ellos ya se estaban aplicando a las negociaciones de otros TLC, siempre adaptándolos a las situaciones, particularidades y circunstancias de cada caso.

En relación a este proceso de transparencia y comunicación, los funcionarios del Mincetur se reunieron durante los preparativos previos a la primera ronda de negociaciones y antes y después de cada ronda; primero con los funcionarios de las diversas reparticiones gubernamentales responsables específicos de las áreas productivas y regulatorias; y luego con los gremios empresariales y representantes de los sindicatos, la academia y la sociedad civil. Asimismo, se aceptó cuanta invitación se recibió para tratar el tema en Lima y sobre todo en el interior del país, tanto en los ámbitos universitarios como profesionales, gremiales y sindicales, así como de la sociedad civil. Por otro lado, las altas autoridades hicieron los pertinentes anuncios y declaraciones a la prensa y participaron, cuando fueron invitados, en los programas de los medios de comunicación del país. Adicionalmente, en momentos necesarios, se encomendaron algunas encuestas para conocer la opinión pública en relación al apoyo a las negociaciones y al eventual acuerdo de libre comercio.

Estas actividades permitieron despejar dudas, inquietudes y preocupaciones de todos los interesados en el TLC Perú-China. Ello permitió obtener el apoyo generalizado al acuerdo y, en su momento, a su puesta en vigencia.

\section{El acuerdo del libre comercio Perú-China ${ }^{17}$}

El 19 de noviembre de 2008, durante la visita de Estado del presidente Hu Jintao al Perú, se anunció la finalización de las negociaciones del acuerdo comercial. El 28 de abril de 2009 se suscribió este TLC, en Beijing. El mismo fue firmado por la ministra Mercedes Aráoz y por el viceministro de Comercio de China, Yi Xiaozhun. El tan importante evento contó con la presencia del primer vicepresidente del Perú, almirante Luis Gianpietri, y por el lado chino concurrió el entonces

\footnotetext{
${ }^{17}$ El texto completo se halla en Mincetur, s/f d.
} 
vicepresidente Xi Jinping. En la misma ceremonia, también se suscribió un Acuerdo de Cooperación Aduanera ${ }^{18}$ y un Memorando de Entendimiento en Cooperación Laboral y Seguridad Social ${ }^{19}$.

El tratado comercial más importante para el Perú con el Asia fue ratificado el 5 de diciembre de 2009, mediante decreto supremo 092-2009-RE. El mismo entró en vigencia el 1 de marzo de 2010, de conformidad con el decreto supremo 005-2010-Mincetur.

El Mincetur resume el acuerdo de la manera siguiente: «[...] en línea con la estrategia peruana de convertirse en el centro de operaciones del Asia en América del Sur, este TLC representa para el Perú la oportunidad de establecer reglas de juego claras, con un marco transparente y previsible, que permita tener un comercio bilateral ordenado, el cual salvaguarde justificadamente los intereses nacionales. Asimismo, brinda una señal positiva que elevará el interés de capitales procedentes de China y de otros países para invertir más activamente en el Perú» (Mincetur, s/f c).

El TLC entre Perú y China comprende 17 capítulos cuyo conjunto contiene los siguientes temas:

- comercio de bienes

- reglas de origen

- defensa comercial

- comercio de servicios

- inversiones

- entrada temporal de personas de negocios

- medidas sanitarias y fitosanitarias

- obstáculos técnicos al comercio

- solución de controversias

\footnotetext{
${ }^{18}$ El Acuerdo de Cooperación Aduanera, como instrumento complementario al TLC, genera obligaciones para que las partes intercambien y validen información oficial sobre el origen y el valor de las mercancías, mejorando el control sobre prácticas aduaneras ilegales en el comercio entre ambos países en aquellos casos donde se presuma situaciones de subvaluación, triangulación, subconteo, contrabando u otros delitos aduaneros. Concretamente el acuerdo permite que las Aduanas soliciten información sobre el valor u origen de una mercancía, que podrá ser utilizada en procesos administrativos y judiciales. «Los sectores productivos nacionales que más se beneficiarán con la aplicación del citado Acuerdo son los de textiles, confecciones, calzado y metalmecánico, quienes durante muchos ańos han solicitado el establecimiento de una herramienta que permita combatir las prácticas de comercio ilegal entre [sic] Perú y [sic] China. ...el Acuerdo de Cooperación Aduanera [...] es probablemente el acuerdo más completo que China haya negociado con otros países» (Mincetur, $s / f$ e).

${ }^{19}$ Por el Memorando de Entendimiento en Cooperación Laboral y Seguridad Social, se cooperará en a) promoción del empleo e información del mercado de trabajo; b) leyes laborales y políticas; c) condiciones de trabajo incluyendo salarios mínimos; d) relaciones laborales y diálogo social; e) seguridad social; f) desempeńo y reforzamiento de sistemas de inspección del trabajo; g) formación profesional; h) otros asuntos que las Partes acuerden (Mincetur, s/f a).
} 
- procedimientos aduaneros

- propiedad intelectual

- cooperación

- transparencia, y

- asuntos institucionales.

El que el TLC Perú-China, incluya mercancías, servicios e inversiones, además de otros asuntos, lo hace acreedor de lo que se denomina acuerdos de libre comercio de segunda generación u OMC+. Este apelativo se le da a los TLC que incluyen disciplinas que son adicionales a las relacionadas al acceso al mercado de mercancías, como es el caso de los servicios y de las inversiones, entre otros y que son más ambiciosos que lo acordado en el ámbito de la OMC.

Entre los aspectos más resaltantes del TLC se puede mencionar que (Mincetur, 2019, p. 3):

- el Perú mantiene de manera indefinida la posibilidad de aplicar el drawback y los regímenes de importación y exportación temporal.

- las mercancías producidas en zonas francas podrán beneficiarse del TLC.

- se promueve la facilitación del comercio mediante regímenes aduaneros que simplifican los trámites que se deben seguir para la admisión temporal de mercancías.

- el Perú puede continuar aplicando el Sistema de Franja de Precios.

- la China no podrá mantener, introducir o reintroducir subsidios a la exportación.

En cuanto al aspecto comercial más importante para los intereses peruanos - el acceso al mercado chino de productos peruanos - lo obtenido para las exportaciones nacionales se sintetiza en el cuadro 2.

A partir del 1 de enero de 2019, fecha de la décima rebaja tarifaria, el 93,6\% de las líneas arancelarias de la China (7.259) están totalmente desgravadas para exportaciones originarias del Perú ${ }^{20}$. Asimismo, China otorgó a los productos originarios del Perú la desgravación arancelaria total de manera inmediata o hasta un plazo máximo de 17 años (hasta el 1 de enero de 2027) al 94,5\% (7336) de sus líneas arancelarias. Por otro lado, China no reducirá sus tarifas de importación a 422 (5,4\%) líneas arancelarias.

\footnotetext{
${ }^{20}$ El procedimiento recíproco de reducciones arancelarias, conforme al Anexo 2, «Eliminación Arancelaria» fue que la primera rebaja de aranceles, correspondiente al ańo 1, se hiciese a la entrada en vigencia del acuerdo, y el ańo 2 corresponde al 1 de enero del ańo siguiente. Es decir la primera rebaja se realizó el 10 de marzo de 2010, la segunda el 1 de enero de 2011 y así sucesivamente. Por lo que a partir del 01 de enero de 2019 ambas partes aplicaron la décima rebaja. Estas rebajas anuales son iguales (es decir lineales), de modo que se aplique el $0 \%$ en el último año correspondiente a su categoría. No siguen esta reducción lineal las líneas arancelarias que se hallan en las categorías E, K y L. Estas tienen un proceso no lineal (Mincetur, s/f c).
} 
Cuadro 2. Condiciones de acceso de las exportaciones peruanas a China

\begin{tabular}{lcc}
\hline Categoría de desgravación & N $^{\circ}$ de líneas & Part. \\
\hline Acceso inmediato & 4747 & $61,2 \%$ \\
\hline B (5 años) & 908 & $11,7 \%$ \\
C (10 años) & 1604 & $20,7 \%$ \\
D (Sin desgravación) & 422 & $5,4 \%$ \\
E (16 años) & 5 & $0,1 \%$ \\
F (8 años) & 14 & $0,2 \%$ \\
G (12 años) & 24 & $0,3 \%$ \\
H (15 años) & 12 & $0,2 \%$ \\
I (17 años) & 20 & $0,3 \%$ \\
K (Uva) & 1 & $0,0 \%$ \\
L (Harina pescado) & 1 & $0,0 \%$ \\
\hline Total & 7758 & $100 \%$ \\
\hline
\end{tabular}

Fuente: Mincetur, 2019, p. 4. Elaboración: Mincetur/DGIECE/DEE.

En este grupo (categoría D: sin desgravación) se encuentran algunos productos pesqueros, café, trigo, arroz, maíz, aceites vegetales, azúcar, tabaco, algunas preparaciones alimenticias, combustibles, urea, polietileno, neumáticos, pieles, madera, papel, televisores, autos, motocicletas. Sin embargo, las reducciones arancelarias totales o parciales benefician a muchos de los productos de interés del Perú. Sobresalen entre ellos colorantes inorgánicos, mango, carne de ave, ajos, palta, cebollas, cacao, fresas frescas, espárrago, capsicum/páprika, selenio, manufacturas de zinc, cobre y hierro, boro, entre otros (Mincetur, 2019, p. 3).

Mención especial se debe hacer al tratamiento arancelario a las exportaciones de uvas y de harina de pescado, ambos productos peruanos de gran interés para la China. Estos productos se hallan en Categorías K y L respectivamente. Para ellos, la China otorgó al Perú un trato preferente similar al que le brindaba a Chile. Esto significa que, desde el momento en que el TLC entró en vigencia (1 de marzo de 2010), los productos peruanos en estas categorías uvas frescas de mesa y harina de pescado comenzaron a ingresar al mercado chino en iguales condiciones arancelarias que los productos chilenos $^{21}$. Asimismo, ambos productos, para los dos países (Perú y Chile) desde el

\footnotetext{
${ }^{21}$ Mincetur, s/f e; Tang, 2017, p. 178; Moreno y Roldán (2013); Dussel (2015); Wise (2016); y, Pérez y Castro (2017) son algunos expertos que han publicado análisis comparativos entre los TLC que la China tiene vigentes
} 
1 e enero de 2015 ingresaron sin aranceles. El esquema de desgravación de estos dos productos se halla en el cuadro 3 .

Cuadro 3. Proceso de desgravación arancelaria para los productos de las categorías K y L

\begin{tabular}{lcc}
\hline & \multicolumn{2}{c}{ Arancel aplicado } \\
\cline { 2 - 3 } Fecha & Uva & Harina de pescado \\
\hline 1 -mar-2010 & $6,5 \%$ & $1,0 \%$ \\
1 -ene-2011 & $5,2 \%$ & $0,8 \%$ \\
1 -ene-2012 & $3,9 \%$ & $0,6 \%$ \\
1 -ene-2013 & $2,6 \%$ & $0,4 \%$ \\
1 -ene-2014 & $1,3 \%$ & $0,2 \%$ \\
1 -ene-2015 & $0,0 \%$ & $0,0 \%$ \\
\hline
\end{tabular}

Fuente: Mincetur, s/f e.

Respecto al acceso al mercado peruano de productos chinos, lo acordado se resume en el siguiente cuadro:

Cuadro 4. Condiciones de acceso de las importaciones peruanas desde China

\begin{tabular}{lcc}
\hline Categoría de desgravación & $\mathrm{N}^{\circ}$ de líneas & Part. \\
\hline Acceso inmediato & 4610 & $62,7 \%$ \\
\hline B (5 años) & 951 & $12,9 \%$ \\
C (10 ańos) & 1055 & $14,4 \%$ \\
D (Sin desgravación) & 592 & $8,1 \%$ \\
E (16 años) & 87 & $1,2 \%$ \\
G (12 años) & 5 & $0,1 \%$ \\
H (15 años) & 22 & $0,3 \%$ \\
J1 (17 años + 4 años de gracia) & 4 & $0,1 \%$ \\
J2 (17 años + 8 años de gracia) & 3 & $0,0 \%$ \\
J3 (17 años + 10 ańos de gracia) & 22 & $0,3 \%$ \\
\hline Total & 7351 & $100 \%$ \\
\hline
\end{tabular}

Fuente: Mincetur, 2019, p. 4. Elaboración: Mincetur/DGIECE/DEE.

actualmente con Latinoamérica: Chile, Perú y Costa Rica. Por su lado, Baumann (2016) analiza comparativamente ocho acuerdos: Chile, Perú, Costa Rica, Singapur, Australia, Corea del Sur, Nueva Zelanda y ASEAN. 
Desde el 1 de enero de 2019, fecha en que se aplicó la décima reducción arancelaria, el 90\% de las líneas arancelarias de las importaciones peruanas desde la China entran libres de derechos tarifarios. Esto es 3,6\% menos de líneas arancelarias que el Perú goza libre de aranceles en sus exportaciones a la China que corresponden a 6.616 líneas arancelarias. En estas se hallan productos de interés chino como celulares, computadoras y sus partes, diversos aparatos eléctricos, productos laminados de acero, urea, entre otros.

Por otro lado, en la categoría D se halla el 8,1\% (952) de las líneas arancelarias. ${ }^{22}$ Estas no están previstas de recibir beneficio arancelario alguno si se tratan de importaciones desde la China. En esta categoría, sobresalen los productos que cuentan con una menor ventaja competitiva, los cuales pertenecen al sector textil y confecciones, calzado y metalmecánico. Estos productos excluidos de la desgravación arancelaria, representan alrededor del 10\% de las importaciones del Perú desde China.

El Perú rebajará aranceles a 91,9\% de sus líneas arancelarias (6.759) a las importaciones procedentes de la China, ya sea de manera inmediata (4.610 líneas arancelarias, $62,7 \%$ ), o de manera gradual, hasta en diecisiete ańos (categoría J). Cabe mencionar que la categoría J, que contiene 29 líneas arancelarias $(0,4 \%)$, se desdobla en tres subcategorías. Ellas corresponden a un proceso de desgravación de diecisiete años con 4, 8 y 10 años de gracia. En otras palabras, durante los primeros años señalados como de gracia, no se lleva a cabo reducción arancelaria alguna para iniciar el proceso de rebaja lineal en los ańos restantes. Es decir que, conforme a lo explicado en la nota 20, a partir del 1 de enero de 2020, se habrá aplicado la primera rebaja arancelaria a las subpartidas incluidas en la sub categoría J3, es decir las que tienen diez años de gracia.

En resumen, se ha logrado que muchos productos peruanos de los sectores agrícolas, pesqueros e industriales ingresen en condiciones preferenciales y competitivas frente a países que también cuentan con TLC con la China. Por otro lado, el acuerdo, además, permite al usuario peruano acceder a insumos más baratos que incrementan la eficiencia industrial local. Ello facilitará la integración de sus producciones en cadenas productivas.

Según el Mincetur (s/f e), este acuerdo: i) representa la oportunidad de establecer reglas de juego claras, con un marco transparente y previsible, que permita tener un comercio bilateral ordenado, el cual salvaguarde justificadamente los intereses nacionales; ii) brinda una señal positiva que elevará el interés de capitales procedentes de China y de otros países para invertir más activamente en el Perú; y iii) ayudará

\footnotetext{
${ }^{22}$ En esta categoría se hallan, en el caso de las exportaciones peruanas a la China, 422 subpartidas arancelarias (5,4\% del total) como se puede apreciar en el cuadro 2 .
} 
a reducir la desviación de comercio generada por los acuerdos que ha firmado China con otros países competidores del Perú, disminuyendo así la brecha entre el arancel cobrado a los productos procedentes de estos países con el arancel cobrado al producto originario peruano.

Finalmente, el acuerdo ha coadyuvado a consolidar más aún la imagen positiva del Perú en el Este asiático y a progresar sustancialmente con el objetivo de convertirnos en el líder del Pacífico Sur y «centro de negocios» en América del Sur.

\section{ElcomercioPerú-China:unanálisisdelosnueveañosdevigenciadel TLCbilateral}

Transcurridos nueve años de vigencia del TLC Perú-China, la estructura del intercambio comercial sigue siendo ventas peruanas de materias primas y productos tradicionales con escaso valor agregado, y compra de bienes manufacturados, algunos de tecnología avanzada con cada vez mayor valor agregado. A esta situación se le conoce como un intercambio interindustrial: materia prima por manufactura (Tang, 2017, p. 176; Canales, 2017, p. 245).

Por otro lado, la creciente exportación de materias primas ha llevado a anunciar la reprimarización de economías como la peruana y su desindustrialización. Adicionalmente hay un retorno de la vigencia de la teoría de la dependencia, al argumentarse que cada vez más el Perú, y otras economías de la región, exportan sobre todo materias primas y cuyo principal comprador es la China (Bittencourt, 2017, pp. 455-460; Gonzáles-Vicente, 2012; Pérez y Castro, 2017, pp. 157-163)²3.

Respecto a los argumentos positivos y negativos sobre los resultados que se tienen del comercio post vigencia del TLC Perú-China, es tal vez más objetivo hacer un análisis del intercambio de mercancías tanto desde el punto de vista del vaso medio lleno como desde el punto de vista del vaso medio vacío.

Usando la información consignada en el más reciente informe del Mincetur (2019) sobre el aprovechamiento del TLC con la China, el cuadro 5 nos muestra la

\footnotetext{
${ }^{23}$ En relación con la Alianza del Pacífico (AP), aplicable por ende al Perú, Marchini (2017) asevera que «las relaciones comerciales de la AP con [sic] China manifiestan un carácter interindustrial, típico de las relaciones centroperiferia de etapas anteriores del capitalismo, que hacen temer la aparición de una nueva dependencia» (p. 282). Sin embargo, es posible argumentar que las relaciones interindustriales y de posible nueva dependencia con la China, en realidad sería adicional no reemplazo a las ya existentes con Estados Unidos y con la Unión Europea. Es decir que en cualquier análisis, positivo o negativo, ello sería, en todo caso, una diversificación de estas relaciones interindustriales y de estas dependencias. Tal vez esta ampliación podría ser vista de manera positiva al tener el Perú ahora hasta tres principales fuentes de importaciones de productos avanzados y tres mercados gigantescos a donde exportar tanto productos tradicionales como no tradicionales. La diferencia importante es que esta dependencia (¿nueva? ¿adicional?), es que sea respecto a un país aún de desarrollo.
} 
evolución de las exportaciones peruanas a la China en los nueve años de vigencia de este acuerdo ${ }^{24}$.

En el año 1 de la vigencia del TLC, el 95,7\% de nuestras exportaciones fueron tradicionales, y el 4,9\% restantes fueron no tradicionales. En el año 9, estos porcentajes fueron $96,2 \%$ y 3,8\% respectivamente. Es decir que, aunque en ambos años nuestras exportaciones son extremadamente centradas en materias primas, la distribución entre ambas prácticamente no ha variado. Lo mismo se puede concluir de las cifras acumuladas de los nueve años de exportaciones. En este caso son 95,7\% y $4,3 \%$ los porcentajes respectivos. Más aún, el dinamismo promedio anual para las exportaciones tradicionales fue de $13,6 \%$ y de $11,4 \%$ para las no tradicionales. Ello podría estar indicando que la tendencia en el largo plazo es hacia una cada vez mayor participación de las exportaciones tradicionales.

Si bien los porcentajes son iluminadores, es fundamental recalcar que en términos absolutos las magnitudes tanto de las exportaciones tradicionales como las de las no tradicionales se han incrementado de manera sustancial. En el caso de las tradicionales en 2,4 veces más (de 5308 a 13123 millones de dólares), y en el de las no tradicionales en 1,9 veces más entre el primer y el noveno año de vigencia del TLC. En otras palabras, lo relevante es que aumentó el valor de las exportaciones no tradicionales. Lo trágico hubiese sido que estas hubiesen disminuido de manera sustantiva. Es decir, una reprimarización absoluta.

Cabe también hacer notar que, independientemente de las cifras y porcentajes usados para el análisis anterior, podría decirse que existe una cierta correlación entre la evolución de la economía china, la del Perú y sus exportaciones a la China (Canales, 2017, p. 246). Así, entre 2013 y 2015 , el PBI de la China fue 7,3\%, 7,3\% y 6,9\% respectivamente, y ha continuado reduciéndose de manera gradual hasta ser en 2018 del 6,6\% (Datosmacro, 2019). El del Perú fue de 5,8\%, 2,4\% y 3,3\%. Es decir, que mientras la China ha ido bajando consecutivamente su tasa de crecimiento ${ }^{25}$, la nuestra ha ido zigzagueando. Sin embargo, nuestras exportaciones totales hacia la China solo descendieron en 2014 (quinto año en el cuadro 5) ${ }^{26}$. En cuanto al comportamiento de nuestras exportaciones no tradicionales, irónicamente alcanzaron un pico en 2014

\footnotetext{
${ }^{24}$ De acuerdo a la metodología usada por el Mincetur, dichos nueve ańos abarcan el periodo comprendido entre marzo 2010 y febrero 2019. Así, el ańo uno va de marzo 2010 a febrero 2011 y así sucesivamente. Cabe entonces aclarar que a 01 de enero de 2019 se realizó la décima rebaja arancelaria conforme a lo explicado en la nota 20 y que corresponde al noveno período de análisis.

${ }^{25}$ Esto es consistente con la «nueva normalidad» de reducir de manera paulatina su crecimiento hacia un $6 \%$ anual. Este objetivo fue anunciado por el gobierno chino en su XII Plan Quinquenal (2011-2015) y en su XIII Plan Quinquenal (2016-2020). En estos documentos se anunció la reorientación de la política económica para convertir a la China en una «sociedad moderadamente próspera,» basada en motores internos como el mayor consumo doméstico y los servicios.

${ }^{26}$ Tomando como referencia los datos del cuadro 5, es decir, períodos de marzo a febrero.
} 
(en sentido contrario a nuestras exportaciones totales, exportaciones primarias, y a la reducción del PBI tanto de la China como del Perú), para luego reducirse en los dos años siguientes, y alcanzar un nuevo máximo en 2018 que aparentemente continuará.

Cuadro 5. Exportaciones peruanas a la China: 9 años del TLC

\begin{tabular}{|c|c|c|c|c|c|c|c|c|c|c|c|c|}
\hline \multirow{2}{*}{$\begin{array}{l}\text { Tipo/ } \\
\text { Sector }\end{array}$} & \multicolumn{9}{|c|}{ US\$ millones } & \multicolumn{2}{|c|}{$\begin{array}{l}9^{\circ} \text { año de } \\
\text { vigencia }\end{array}$} & \multirow{2}{*}{$\begin{array}{l}\text { Var, } \\
\text { prom, } \\
\text { anual }\end{array}$} \\
\hline & $\begin{array}{c}1^{\circ} \\
\text { ańo }\end{array}$ & $\begin{array}{c}2^{\circ} \\
\text { año }\end{array}$ & $\begin{array}{c}3^{\circ} \\
\text { ańo }\end{array}$ & $\begin{array}{l}4^{\circ} \\
\text { año }\end{array}$ & $\begin{array}{l}5^{\circ} \\
\text { ańo }\end{array}$ & $\begin{array}{c}6^{\circ} \\
\text { ańo }\end{array}$ & $\begin{array}{c}7^{\circ} \\
\text { ańo }\end{array}$ & $\begin{array}{c}8^{\circ} \\
\text { año }\end{array}$ & $\begin{array}{c}9^{\circ} \\
\text { ańo }\end{array}$ & $\begin{array}{l}\text { US\$ } \\
\text { mill, }\end{array}$ & Part, & \\
\hline Total & 5579 & 7321 & 7484 & 7858 & 6652 & 7409 & 9445 & 11451 & 13636 & 76835 & $100,0 \%$ & $13,5 \%$ \\
\hline Tradicional & 5308 & 6984 & 7128 & 7462 & 6186 & 7106 & 9173 & 11051 & 13123 & 73521 & $95,7 \%$ & $13,6 \%$ \\
\hline Agrícola & 0,9 & 2,8 & 5,3 & 5,1 & 6,3 & 18,3 & 9,2 & 13,6 & 10,6 & 72,1 & $0,1 \%$ & $36,1 \%$ \\
\hline Minero & 4395 & 5724 & 6367 & 6289 & 5692 & 6079 & 8117 & 10025 & 11468 & 64157 & $83,5 \%$ & $15,1 \%$ \\
\hline Pesquero & 778 & 1218,9 & 755,6 & 1109 & 487,8 & 950,4 & 942,3 & 973,6 & 1514 & 8730 & $11,4 \%$ & $8,1 \%$ \\
\hline $\begin{array}{l}\text { Petróleo y } \\
\text { gas natural }\end{array}$ & 135 & 37,8 & & 58,1 & 0 & 58,6 & 104,1 & 38,6 & 130,5 & 562,7 & $0,7 \%$ & $-3,8 \%$ \\
\hline $\begin{array}{l}\text { No } \\
\text { tradicional }\end{array}$ & 270,9 & 337,4 & 355,6 & 396,5 & 465,9 & 303,5 & 271,8 & 399,5 & 512,8 & 3314 & $4,3 \%$ & $11,4 \%$ \\
\hline $\begin{array}{l}\text { Agrope- } \\
\text { cuario }\end{array}$ & 25,6 & 33,7 & 60,2 & 86,4 & 109,2 & 81,5 & 68,4 & 112,5 & 151,5 & 729,1 & $0,9 \%$ & $31,0 \%$ \\
\hline Artesanías & 0 & - & - & - & 0 & 0 & - & 0 & 0 & 0 & $0,0 \%$ & $0,0 \%$ \\
\hline $\begin{array}{l}\text { Maderas y } \\
\text { papeles }\end{array}$ & 81,8 & 56,7 & 52,7 & 59,8 & 62,3 & 56,6 & 59,7 & 56,7 & 52,9 & 539,1 & $0,7 \%$ & $-3,5 \%$ \\
\hline $\begin{array}{l}\text { Metal } \\
\text { mecánico }\end{array}$ & 1,1 & 2,9 & 1,4 & 3,9 & 1,2 & 0,9 & 1 & 1,7 & 2 & 16,2 & $0,0 \%$ & $20,3 \%$ \\
\hline $\begin{array}{l}\text { Minería no } \\
\text { metálica }\end{array}$ & 0,2 & 1,7 & 0,7 & 0,3 & 1,3 & 0,3 & 1 & 1,5 & 0,9 & 7,8 & $0,0 \%$ & $36,6 \%$ \\
\hline Pesquero & 95,7 & 169,6 & 178,3 & 169,4 & 228,8 & 121,3 & 86,8 & 128,8 & 218,1 & 1397 & $1,8 \%$ & $16,5 \%$ \\
\hline $\begin{array}{l}\text { Pieles y } \\
\text { cueros }\end{array}$ & 0,5 & 3,4 & 2,1 & 4,1 & 4,1 & 10,6 & 10,2 & 8,5 & 1,2 & 44,6 & $0,1 \%$ & $28,3 \%$ \\
\hline Químico & 38,2 & 39,3 & 31 & 30,6 & 22,2 & 9,3 & 18,5 & 23,1 & 30 & 242,1 & $0,3 \%$ & $2,3 \%$ \\
\hline $\begin{array}{l}\text { Sidero- } \\
\text { metalúrgico }\end{array}$ & 5,2 & 9,5 & 9,9 & 18,9 & 5 & 3,5 & 2,7 & 3,5 & 2,7 & 61 & $0,1 \%$ & $-6,0 \%$ \\
\hline Textil & 22,4 & 20,3 & 19,2 & 23 & 31,6 & 19,3 & 23,4 & 62,3 & 52,8 & 274,4 & $0,4 \%$ & $10,0 \%$ \\
\hline $\begin{array}{l}\text { Varios (inc. } \\
\text { joyería) }\end{array}$ & 0,1 & 0,2 & 0,2 & 0,2 & 0,2 & 0,1 & 0 & 0,8 & 0,6 & 2,5 & $0,0 \%$ & $23,1 \%$ \\
\hline
\end{tabular}

Fuente: Mincetur, 2019, p. 6. Elaboración: Mincetur/DGIECE/DEE.

Lo anterior podría implicar que en el largo plazo, las exportaciones tradicionales, en especial los minerales como el cobre (nuestra exportación más importante), podrían 
disminuir continuamente por el doble efecto: el de la reducción de la demanda china (una de las mayores si no la mayor compradora de este metal y de otros minerales) y, el de su concomitante reducción en el precio internacional ${ }^{27}$. Si bien, no está en manos del Perú evitar una situación como esta, es necesario preguntarse si esta dependencia adicional (a la que se supone tenemos con EE.UU. y con Europa) es beneficiosa o no. ¿No sería una situación aún menos conveniente que nuestras exportaciones totales a la China disminuyesen sostenidamente debido tanto a la reducción de nuestras ventas a este país de nuestros productos tradicionales y peor aún de la reducción de las exportaciones no tradicionales? ${ }^{28}$.

Por otro lado, teniendo como muy posible un futuro como este, y al depender nuestra economía en mucho de nuestro comercio exterior, en especial de nuestras exportaciones, es fundamental que se intensifique la diversificación de nuestros mercados y de nuestros productos, sobre todo los que contengan mayor valor agregado ${ }^{29}$. En este sentido, el sector agroexportador no tradicional ha mostrado un dinamismo creciente en la magnitud y características de sus exportaciones y la diversificación de su canasta ${ }^{30}$. Su crecimiento anual ha sido del $31 \%$, en los 9 años de vigencia del TLC, es decir casi 6 veces más, desde 25.6 millones de USD en 2010, primer año del TLC, a 151.5 millones de dólares en el noveno ańo (véase cuadro 5) 31 .

Como ya se ha mencionado, nuestro comercio es interindustrial. El valor de nuestras exportaciones tradicionales es inmensamente superior a la de nuestras exportaciones no tradicionales. Los porcentajes así lo demuestran. Y, aunque los montos absolutos

\footnotetext{
27 «[...] el menor crecimiento de la economía y la menor inversión en infraestructura [en la China] podría afectar notablemente nuestros envíos de productos tradicionales, principalmente de minerales.» (ComexPerú, 2019b).

${ }^{28}$ Nada augura que las relaciones comerciales interindustriales que, como ya se ha mencionado, caracterizan a las que mantenemos por larga data con EE.UU. y la Unión Europea, cambiarán en el tiempo. Sin embargo, al igual que nuestro comercio con la China, es posible esperar que nuestras exportaciones no tradicionales se incrementen en términos absolutos (y mejor aún en términos relativos).

${ }^{29}$ Para ello el sector público, el sector privado, la academia y otros actores deberán continuar el desarrollo de medidas e instrumentos pro exportadores para un uso más eficiente y efectivo de nuestros recursos naturales y humanos con miras a avanzar a incrementar los mercados con acceso preferencial y aumentar la cantidad y variedad de las exportaciones, en especial las no tradicionales

30 «Es innegable el extraordinario desempeńo del sector agroexportador, hoy el segundo sector exportador y gran generador de empleo, formalidad, reducción de pobreza y oportunidades en las zonas rurales de nuestro país» (Luna, 2019). Sobresalen por su magnitud y/o dinamismo de crecimiento anual productos como: calamares, uvas, pelos de alpaca, arándanos, paltas, algas, huevas y lechas de pescados, tablillas y frisos de madera (Mincetur, 2019, p. 11).

A nivel global, los principales productos de exportación son las uvas, las paltas, los arándanos, los espárragos, la quinua, nueces del Brasil y mangos (Luna, 2019).

${ }^{31}$ Hay que señalar que las exportaciones del sector agrícola (es decir los productos tradicionales de exportación de este sector), de acuerdo con la información del cuadro 5, tuvo un incremento promedio anual de 36,1\%. Ello es debido a que las exportaciones en el primer año fueron de solo 900 mil dólares; mientras que el sector agropecuario (productos no tradicionales) exportó cerca de 30 millones de dólares en dicho ańo. En ese mismo sentido se debe entender el dinamismo del sector de minería no metálica (exportaciones no tradicionales) que ostenta un 36,6\% de crecimiento promedio anual en los nueve años de vigencia de este acuerdo.
} 
de ambos tipos de exportaciones han aumentado, habría que preguntarse si es que sin el TLC nuestras exportaciones no tradicionales hubiesen aumentando al ritmo del $11,4 \%$ anual al menos para que se mantenga esta distribución de la estructura de nuestras exportaciones. O tal vez, sin el TLC podría haber sucedido que el porcentaje de las exportaciones tradiciones respecto al total de las exportaciones pudiese haber sido aún mayor, y continuar estando concentradas en unos pocos minerales. Mientras que a su vez, las exportaciones no tradicionales podrían haberse reducido. Un escenario más negativo, pero posible, de no tener un acuerdo de libre comercio con la China, es que también nuestras exportaciones tradicionales tengan menor dinamismo o peor aún, que disminuyan ${ }^{32}$.

Por el otro lado del comercio interindustrial, nuestras importaciones son en su mayoría manufacturas con cada vez más valor agregado y muy diversificadas. Así, las 15 principales subpartidas importadas en el octavo y en el noveno año de vigencia del TLC solo constituyeron el 27\% del total importado en ambos años (Mincetur, 2019, p. 17). Mientras que las 15 subpartidas más exportadas en dichos años alcanzaron el $94 \%$ y el $97 \%$ del total exportado; de ellos, el cobre fue $62 \%$ y $63 \%$ en dichos años (p. 9). Más aún, las 15 principales exportaciones tradicionales constituyen, en el octavo y en el noveno ańo, el $97 \%$ y el $99,5 \%$ de las exportaciones tradicionales, respectivamente (p. 10). A su vez las 15 principales exportaciones no tradicionales en el octavo y en el noveno año representan el $83 \%$ y el $90 \%$ del total de las exportaciones no tradicionales (p. 11).

A pesar de esta estructura interindustrial, es posible notar que de acuerdo a la clasificación cuotidiana de las importaciones por el uso / destino económico (cuadro 6), la menor proporción de las mismas son bienes de consumo. Así en los nueve años de vigencia del TLC, solo el $29 \%$ de las importaciones han sido de este rubro. Por otro lado, en ese periodo, el 26\% fueron compras desde la China de materias primas e insumos; y del $45 \%$ fueron bienes de capital. En otras palabras, el $71 \%$ de las importaciones provenientes de dicho país fueron productos que sirven a la industria y la agricultura peruana para producir otros bienes. La mayor magnitud para el consumo doméstico a menores costos de producción, pero crecientemente para las exportaciones.

Adicionalmente, es necesario notar que en cada uno de los nueve ańos de vigencia, las importaciones de bienes de capital han sido mayores a las de los bienes de consumo.

\footnotetext{
32 Estos efectos podrían ser casos de lo que se conoce en la teoría de la integración económica como desviación de comercio. En estas situaciones, la desviación de comercio funcionaría de la siguiente manera. Si el Perú no tuviese un TLC con la China, sus exportaciones no gozarían de la reducción de aranceles. Estas reducciones sí serían aplicadas a las exportaciones de otros países que sí tienen TLC vigentes con la China. Ello permitiría a estas últimas ingresar al mercado chino a precios más bajos en relación a las exportaciones peruanas. Con ello, las exportaciones de otros países desplazan a las peruanas, pudiéndose dar el caso de estancamiento de nuestras exportaciones, o peor aún, su disminución.
} 
Cuadro 6. Importaciones peruanas desde la China: nueve años del TLC

\begin{tabular}{llrrrrr}
\hline CUODE & & $\begin{array}{c}\text { Bienes de } \\
\text { consumo }\end{array}$ & $\begin{array}{c}\text { Materias } \\
\text { primas y } \\
\text { productos } \\
\text { intermedios }\end{array}$ & $\begin{array}{c}\text { Bienes de } \\
\text { capital y } \\
\text { materiales de } \\
\text { construcción }\end{array}$ & Diversos & $\begin{array}{c}\text { Total } \\
\text { general }\end{array}$ \\
\hline & $1^{\circ}$ año & 1520,8 & 1390,4 & 2418,1 & 0,1 & 5329,3 \\
& $2^{\circ}$ año & 2011,9 & 1603,6 & 3002,3 & 0,8 & 6618,6 \\
& $3^{\circ}$ año & 2316,3 & 1987,5 & 3627,9 & 0,2 & 7931,9 \\
US\$ & $4^{\circ}$ año & 2593,8 & 2001,0 & 3875,2 & 0,4 & 8470,4 \\
millones & $5^{\circ}$ año & 2561,1 & 2353,1 & 4169,1 & 1,0 & 9084,4 \\
& $6^{\circ}$ año & 2471,1 & 2149,1 & 3902,3 & 0,7 & 8523,2 \\
& $7^{\circ}$ año & 2312,0 & 2150,9 & 3741,3 & 0,3 & 8204,5 \\
& $8^{\circ}$ año & 2670,5 & 2475,3 & 3969,5 & 0,3 & 9115,5 \\
\hline $9^{\circ}$ ańo de & $9^{\circ}$ año & 2973,1 & 2876,9 & 4348,2 & 0,1 & 10198,3 \\
\cline { 2 - 8 } vigencia & Part. & $29,2 \%$ & $25,8 \%$ & $45,0 \%$ & $0,0 \%$ & $100,0 \%$ \\
\hline Variación prom. anual & $13,4 \%$ & $15,3 \%$ & $11,3 \%$ & $13,3 \%$ & $12,9 \%$ \\
\hline
\end{tabular}

Fuente: Mincetur, 2019, p. 15. Elaboración: Mincetur/DGIECE/DEE.

Si bien, el hecho que las importaciones totales peruanas tengan una estructura similar, es decir que las materias primas, insumos y bienes de capital sean la mayoría de las importaciones ${ }^{33}$, es preciso notar la influencia del TLC en dichas importaciones. Así de acuerdo con el cuadro 7, el 100\% de las importaciones desde la China de bienes de capital ingresaron al país pagando cero de aranceles. Por su lado el 70\% de las importaciones de los insumos y materias primas tuvieron ese mismo trato arancelario. En contraste, solo el 34\% de las importaciones de bienes de consumo ingresaron sin el pago de aranceles ${ }^{34}$. Esta situación permite «[...] la caída de los precios de las importaciones peruanas desde China» (ComexPerú, 2019 a), y por ende producir a menores costos y más eficiente y competitivamente. Además es posible intuir, que en el largo plazo, de mantenerse esta estructura de importaciones mayoritariamente para producir otros bienes, nuestras exportaciones podrían ser más diversificadas, con mayor valor agregado y con crecientes posibilidades de formar parte de cadenas globales de valor.

\footnotetext{
33 El cuadro 6 indica que en el año nueve la distribución de nuestras importaciones totales es de 29,2\% de bienes de consumo, $25,8 \% \%$ de materias primas y productos intermedios y $45 \%$ de bienes de capital.

${ }^{34}$ Sin embargo, cabe notar que a partir del año 10 (marzo de 2019), si se mantiene la misma proporción de importaciones, el $67 \%$ de las importaciones de bienes de consumo y el $85 \%$ de insumos y materias primas tienen acceso al mercado peruano libre de aranceles.
} 
Cuadro 7. Importaciones Perú-China, según CUODE y categoría de desgravación $9^{\circ}$ ańo de vigencia del TLC Perú-China

\begin{tabular}{lrr}
\hline \multirow{2}{*}{ CUODE } & \multicolumn{2}{c}{$9^{\circ}$ ańo de vigencia } \\
\cline { 2 - 3 } & \multicolumn{1}{c}{ Part. } & \multicolumn{1}{c}{ US\$. } \\
\hline Bienes de consumo & $100,0 \%$ & 2973.1 \\
\hline Acceso libre* & $33,7 \%$ & 1001.7 \\
\hline 10 ańos & $33,1 \%$ & 984.8 \\
15 años & $0,0 \%$ & 0.0 \\
16 ańos & $9,5 \%$ & 281.5 \\
17 ańos +10 gracia & $0,0 \%$ & 0.0 \\
Sin desgravación & $23,7 \%$ & 705.2 \\
\hline Materias primas y productos intermedios & $100,0 \%$ & 2876.9 \\
\hline Acceso libre* & $70,23 \%$ & 2020.8 \\
\hline 10 ańos & $14,8 \%$ & 426.6 \\
16 ańos & $5,2 \%$ & 149.2 \\
Sin desgravación & $9,7 \%$ & 280.3 \\
\hline Bienes de capital y materiales de construcción & $100,0 \%$ & 4348.2 \\
\hline Acceso libre* & $100,0 \%$ & 4348.2 \\
\hline Diversos & $100,0 \%$ & 0.1 \\
\hline Acceso libre* & $100,0 \%$ & 0.1 \\
\hline Total general & & 10198.3 \\
\hline
\end{tabular}

Fuente: Mincetur, 2019. Elaboración: Mincetur/DGIECE/DEE en base a información de la SUNAT.

Sin embargo, hay que reiterar que, eventualmente el comercio entre ambos países quedará libre de gravámenes, exceptuando las subpartidas incluidas en la categoría de «Sin desgravación» de las dos partes. Al respecto, cabe mencionar que en virtud de los memorandos de entendimiento entre ambos países, se decidió llevar a cabo negociaciones para optimizar este TLC $^{35}$. Es de suponer, que entre otras cosas, se podría acordar acelerar la desgravación de las subpartidas que aún no tienen libre acceso, y

\footnotetext{
35 Mediante el memorándum firmado el 21 de noviembre de 2016, durante la reunión bilateral entre los presidentes Pedro Pablo Kuczynski y Xi Jinping, en el marco de las reuniones de Líderes de las Economías de APEC, en Lima, se acordó un estudio conjunto sobre la optimización del TLC, con miras a maximizar los beneficios derivados del TLC. En el marco de la reunión de ministros de Relaciones Exteriores y Comercio de APEC, en Port Moresby, Papúa Nueva Guinea, se firmó el memorándum por el que se inician oficialmente las negociaciones para la optimización del TLC. También se instruye a los funcionarios a realizar las mismas de manera expedita. En los primeros días de abril de 2019 se realizó la primera reunión y están previstas reuniones en junio y en agosto de este mismo
} 
tal vez, reducir la lista de subpartidas incluidas en la categoría de "Sin desgravación» de ambos países ${ }^{36}$. Ello solo hará que los beneficios se potencien aún más, lo que redundará en el aumento del bienestar económico mutuo.

Analizando los datos agregados, los nueve años de vigencia del TLC bilateral, muestran que la evolución de estos indicadores globales del comercio bilateral permite concluir de manera optimista (cuadro 8).

Las exportaciones totales tuvieron un crecimiento promedio anual de 13,5\%, pasando de 5580 millones de dólares a 13636 entre el primer año (marzo 2010-febrero 2011) y el noveno año (marzo 2018-febrero 2019) de vigencia del acuerdo. En los nueve ańos las exportaciones a la China totalizaron 76835 millones de dólares.

Por su parte las importaciones totales también crecieron de manera robusta. En este caso, en 12,9\% promedio anual. En términos absolutos, esto significó pasar de 5329 millones de dólares en el primer año a 10198 millones en el noveno año. Ello ha conllevado que al final del año nueve, las importaciones procedentes de la China hayan alcanzado la cifra total de 73476 millones de dólares.

Por lo tanto, el intercambio comercial total (exportaciones más importaciones), también tuvo un dinámico comportamiento. Este indicador creció en 13,2\% promedio anual. En los nueve años, el comercio total acumulado llegó a los 150311 millones de dólares. Esta importante magnitud es el reflejo del constante aumento de las exportaciones y de las importaciones ${ }^{37}$. La suma de ellas, pasaron en el año uno de 10909 millones de dólares a 23835 millones de dólares en el año nueve.

El saldo comercial (exportaciones menos importaciones) ha sido positivo para el Perú. En los nueve ańos de vigencia del TLC, de manera acumulada, nuestras exportaciones han superado a nuestras importaciones. Siendo este superávit comercial peruano de 3359 millones de dólares. Ello a pesar de que refleja saldos deficitarios peruanos en cuatro años consecutivos: del tercero (marzo 2012-febrero 2013) al sexto (marzo 2015-febrero 2016). Estos déficits fueron crecientes hasta el quinto año, para reducirse en el sexto, y volver el saldo comercial a ser superavitario y creciente en los años siete, ocho y nueve. De hecho, en cada uno de estos años ha ido incrementándose el saldo comercial positivo para el Perú ${ }^{38}$.

\footnotetext{
año (El Comercio, 2019). Se espera que en el marco de las reuniones de la Cumbre APEC en Santiago de Chile en noviembre de 2019, se anuncie la finalización o avances importantes en estas negociaciones de optimización.

36 Asimismo, es de suponer que se ańadirán disciplinas a las ya negociadas y se optimizarán estas últimas.

37 Excepto en el quinto año en el caso de las exportaciones totales, y en el sexto y séptimo años en el caso de las importaciones.

38 No obstante estos resultados, saldos superavitarios en la balanza comercial no son siempre necesariamente buenos resultados. Igualmente, saldo deficitarios tampoco son ipso facto, resultados negativos.
} 
Cuadro 8. Comercio Perú-China en los nueve años de vigencia del TLC

\begin{tabular}{|c|c|c|c|c|c|}
\hline \multicolumn{2}{|c|}{$\begin{array}{l}\text { Flujo comercial } \\
\text { Millones USD }\end{array}$} & $\begin{array}{c}\text { Exportaciones } \\
\text { (FOB) }\end{array}$ & $\begin{array}{c}\text { Importaciones } \\
\text { (CIF) }\end{array}$ & $\begin{array}{c}\text { Saldo } \\
\text { comercial }\end{array}$ & $\begin{array}{c}\text { Intercambio } \\
\text { comercial }\end{array}$ \\
\hline $\begin{array}{c}\text { Ańo } \\
\text { previo }\end{array}$ & (Mar 09 - Feb 10) & 4369.60 & 3417.00 & 952.6 & 7786.60 \\
\hline $1^{\circ}$ año & (Mar 10 - Feb 11) & 5579.30 & 5329.30 & 250 & 10908.60 \\
\hline $2^{\circ}$ año & (Mar 11 - Feb 12) & 7321.20 & 6618.60 & 702.6 & 13939.80 \\
\hline $3^{\circ}$ año & (Mar 12 - Feb 13) & 7483.50 & 7931.90 & -448.3 & 15415.40 \\
\hline $4^{\circ}$ año & (Mar 13 - Feb 14) & 7858.20 & 8470.40 & -612.2 & 16328.60 \\
\hline $5^{\circ}$ año & (Mar $14-$ Feb 15) & 6651.90 & 9084.40 & -2432.40 & 15736.30 \\
\hline $6^{\circ}$ año & (Mar 15 - Feb 16) & 7409.50 & 8523.20 & -1113.70 & 15932.60 \\
\hline $7^{\circ}$ año & (Mar 16 - Feb 17) & 9444.50 & 8204.50 & 1240.00 & 17649.00 \\
\hline $8^{\circ}$ año & (Mar 17 - Feb 18) & 11450.70 & 9115.50 & 2335.20 & 20566.30 \\
\hline $9^{\circ}$ año & (Mar 18 - Feb 19) & 13636.20 & 10198.30 & 3437.90 & 23834.60 \\
\hline \multicolumn{2}{|c|}{ Acumulado 9 ańos } & 76835.10 & 73476.00 & 3359.10 & 150311.1 \\
\hline \multicolumn{2}{|c|}{ Crec. prom. anual (9 años) } & $13,50 \%$ & $12,90 \%$ & $15,30 \%$ & $13,20 \%$ \\
\hline
\end{tabular}

Fuente: elaboración a partir de los datos de cuadros 5 y 6.

Este análisis básico de las cifras a nivel macro, nos muestra que con lo que hemos vendido a la China en estos nueve años de vigencia del TLC, hemos podido comprar desde ese país, y también tener un saldo acumulado a nuestro favor ${ }^{39}$. Y si bien nuestras exportaciones tradicionales son de lejos las más preponderantes, no por ello estas dejan de ser importantes e influyentes en la economía doméstica. Por otro lado, las crecientes importaciones han sido mayoritariamente para producir productos a costos menores. Más aún, el TLC ha contribuido a que la China sea desde 2011 nuestro principal socio comercial. Por lo que en el fondo, la pregunta contra fáctica relevante podría ser que, sin el TLC, ¿nuestras exportaciones, sobre todo las no tradicionales, hubiesen podido incrementarse de la forma como lo han hecho y si estas puedan tener ahora un futuro cada vez más promisorio en el mercado chino?5.

\footnotetext{
39 «Las cifras demuestran que el acuerdo entre nuestro país y China ha sido muy beneficioso y continua siéndolo tras 9 años» (ComexPerú, 2019a).
} 


\section{Conclusiones}

El acuerdo de libre comercio con la China es el segundo más importante negociado por el Perú y también el segundo con un país asiático. Este acuerdo ha sido uno de los factores que han contribuido de alguna manera a que desde $2011^{40}$ la China sea nuestro primer socio comercial ${ }^{11}$. Es tanto nuestro principal destino de nuestras exportaciones como la principal fuente de nuestras importaciones.

La preparación para llevar a cabo la negociación de este TLC tuvo características especiales. Se tuvo que superar el impasse del reconocimiento prematuro por parte del Perú de la calidad de economía de mercado a la China. Es probable que ello haya demorado el inicio de las negociaciones.

El proceso de las negociaciones fue similar al que se aplicó por primera vez para las negociaciones con EE.UU. Si bien este proceso fue aplicado a otras negociaciones anteriores a la negociación del TLC con la China, este fue particularmente especial por la celeridad a la se llegaron a acuerdos y se concluyeron las negociaciones. Ello reflejó el gran interés y la importancia económica y política de lograr rápidamente un acuerdo mutuamente beneficioso. Hasta el momento, este es el acuerdo que menos tiempo ha tomado en negociarse.

Por otro lado, dada la importancia creciente de la China en el comercio y en el mercado peruano, hubo un interés muy grande por parte de los actores relevantes en el proceso de la negociación. Actores relevantes de amplio rango, desde los interesados en los potenciales emprendimientos de ventas a este mercado, como los actores relacionados a los crecientes beneficios derivados de las compras de bienes procedentes de la China que otros actores consideraban con aprehensión, porque ingresarían al mercado peruano productos que podrían competir con los peruanos debido a facilidades otorgadas por el gobierno chino haciendo de estos productos más baratos que los nacionales. Las importantes contribuciones de estos actores permitieron a los negociadores tener un mucho mejor conocimiento de las sensibilidades de estos actores, sobre todo los del sector manufacturero y del agrícola. Además, permitió acordar medidas de protección para situaciones en que estas importaciones estuviesen causando probados efectos negativos en el mercado peruano.

A los nueve ańos de vigencia del TLC, es posible seguir afirmando que ambas partes se han beneficiado. Si bien la estructura del comercio es interindustrial (exportamos materia prima e importamos manufacturas), nuestras exportaciones no tradicionales han crecido consistentemente y se avizora un futuro positivo para ellas, sobre todo las

\footnotetext{
${ }^{40}$ Coincidente con que ya estaba en vigencia el acuerdo de libre comercio.

${ }^{41}$ En 2013 China se convirtió en nuestro segundo socio comercial.
} 
del sector agroindustrial no tradicional. Ello en virtud, tanto de la política doméstica y de los recursos peruanos para incrementar su producción y diversificación productiva en estas áreas, así como debido a la política económica china de elevar su consumo doméstico. El reto sigue en pie: continuar incrementando nuestro comercio bilateral con nuestro mayor socio comercial promoviendo mayor eficiencia y competitividad para maximizar el aprovechamiento de las oportunidades que ofrece el dinámico y variable mercado chino.

\section{Referencias bibliográficas}

Baumann, R. (Junio de 2016). Hecho a medida. Tratados más flexibles. Integración y Comercio $40,150-175$.

Bianco, C. (11 de noviembre de 2016). Supermercado chino. China como economía de mercado. Ser o no ser, ¿esa es la cuestión? BORDES. Revista de Politica, Derecho y Sociedad, 1(3), 15-24. Recuperado de http://revistabordes.com.ar/wp-content/ uploads/2017/03/2_Supermercado_Chino.pdf

Bittencourt, G. (2017). ¿Es posible una estrategia latinoamericana hacia las inversiones chinas? En E. Dussel (coord.). América Latina y el Caribe y China. Economía, comercio e inversión (pp. 449-470). Ciudad de México: Unión de Universidades de América Latina y el Caribe.

Canales, A. (2017). Impacto de China en la economía peruana. En E. Dussel (coord.). América Latina y el Caribe y China. Economía, comercio e inversión (pp. 235-256). Ciudad de México: Unión de Universidades de América Latina y el Caribe.

Chan, J. (2008). APEC y el Perú. Guía sobre el foro de Cooperación Económica Asia-Pacífico y la participación del Perú. Lima: Fondo Editorial de la Universidad de Lima.

Chan, J. (2018). Preparación y organización doméstica para las negociaciones del TLC Perú-EEUU. Agenda Internacional, 36, 191-216. https://doi.org/10.18800/ agenda.201801.010

ComexPerú (5 de abril de 2019). Una China cada vez más libre. Semanario ComexPerú(979). Recuperado de https://www.comexperu.org.pe/articulo/una-china-cada-vez-mas-libre

ComexPerú (9 de abril de 2019). A 9 ańos del TLC con China. Semanario ComexPerú(974). Recuperado de https://www.comexperu.org.pelarticulo/a-9-anos-del-tlc-con-china

Congreso de la República del Perú (s.f.). Memorando de Entendimiento sobre el fortalecimiento de las Relaciones Económicas y Comerciales entre el Ministerio de Comercio Exterior y Turismo de la República del Perú y el Ministerio de Comercio de la República Popular China. Recuperado de http://www2.congreso.gob.pe/sicr/cendocbib/con2_uibd.nsf/ F244D58FDCEB080B052576CB0072A42D/\$FILE/CHINA_MEMORANDUM_DE_ ENTENDIMIENTO_FORTALECIMIENTO_RELACIONES_ECONOMICAS.pdf

Datosmacro - Expansión (15 de abril de 2019). PIB de China. Recuperado de https://datosmacro.expansion.com/pib/china 
Dussel, E. (2015). China's Evolving Role in Latin America: Can it Be a Win-Win? Washington, D.C.: Atlantic Council.

ElComercio (25deabrilde2019). TercerarondadenegociacionesparaoptimizarelTLCPerú-China seríaenagosto. Recuperadoel30deabrilde2019 dehttps://elcomercio.pe/economia/peru/ tercera-ronda-negociaciones-optimizar-tlc-peru-china-seria-agosto-noticia-629905

García-Corrochano, L. y Tang, R. (2011). Las relaciones entre el Perú y China. Lima: Instituto de Estudios Internacionales (IDEI) de la Pontificia Universidad Católica del Perú e Instituto Confucio.

González-Vicente, R. (2012). The Political Economy of Sino-Peruvian Relations: A New Dependency? Journal of Current Chinese Affairs, 41(1), 97-131.

Luna, J. (26 de abril de 2019). Agroexportación. Semanario Comex(981). Recuperado de https://www.comexperu.org.pe/articulo/agroexportacion-981

Marchini, G. (2017). La Alianza del Pacífico y China: ¿hacia una relación más diversificada? En E. Dussel (coord.), América Latina y el Caribe y China. Economía, comercio e inversión 2017 (pp. 279-298). Ciudad de México: Unión de Universidades de América Latina y el Caribe.

Ministerio de Comercio Exterior y Turismo del Perú - Mincetur (2019). Estudio de Aprovechamiento del TLC Perú-China: $9^{\circ}$ año de vigencia del TLC. Lima: Ministerio de Comercio Exterior y Turismo del Perú, Dirección General de Investigación y Estudios sobre Comercio Exterior. Dirección de Estudios Económicos.

Ministerio de Comercio Exterior y Turismo del Perú - Mincetur (s/f a). Sobre el acuerdo Perú - China. Acuerdos Comerciales. Recuperado de http://www.acuerdoscomerciales. gob.pe/index.php?option=com_content $\&$ view=category\&layout=blog $\&$ id $=38 \& \mathrm{It}$ emid $=55$

Ministerio de Comercio Exterior y Turismo del Perú - Mincetur (s/f b). Perú-China: Tratado de Libre Comercio - Estudio Conjunto de Factibilidad. Acuerdos Comerciales. Recuperado de http://www.acuerdoscomerciales.gob.pe/images/stories/china/docs/ Peru_China_JFS_Final_espanol.pdf

Ministerio de Comercio Exterior y Turismo del Perú - Mincetur (s/f c). Tratado de Libre Comercio entre el Perú y China. Acuerdos Comerciales. Recuperado de http://www. acuerdoscomerciales.gob.pe/index.php?option=com_content $\&$ view=category\&layou $\mathrm{t}=\mathrm{blog} \& \mathrm{id}=42 \&$ Itemid $=59$

Ministerio de Comercio Exterior y Turismo del Perú - Mincetur (s/f d). Textos del Acuerdo. Acuerdos Comerciales. Recuperado de http:/www.acuerdoscomerciales.gob.pe/index. php?option=com_content $\&$ view=category $\&$ layout $=$ blog $\& i d=39 \&$ Itemid $=56$

Ministerio de Comercio Exterior y Turismo del Perú - Mincetur (s/f e). Preguntas Frecuentes. Acuerdos Comerciales. Recuperado de http://www.acuerdoscomerciales.gob.pe/index. php?option=com_content $\&$ view $=$ category $\&$ layout $=$ blog $\& i d=41 \&$ Itemid $=58$

Morales, C. (2017). El comercio del sector alimentario entre América Latina y el Caribe y China después de su acceso a la Organización Mundial del Comercio. En E. Dussel (coord.), América Latina y el Caribe y China. Economía, comercio e inversión 2017 (pp. 515-532). Ciudad de México: Unión de Universidades de América Latina y el Caribe. 
Moreno, M. y Roldán, A. (2013). Análisis de los tratados de libre comercio suscritos entre la República Popular China y los países de América Latina. En E. Viera (ed.), La Transformación de China y sus efectos para Colombia (pp. 225-248). Bogotá: Cesa.

Novak, F. y Namihas, S. (2016). Las relaciones bilaterales entre el Perú y la república Popular China (2006-2016). En J. Caillaux, F. Novak y M. Ruiz (eds.), Las relaciones de China con América Latina y el ferrocarril bioceánico Brasil-Perú (pp. 37-60). Lima: SPDA, IDEI-PUCP.

Pérez, C. y Castro, A. (2017). China y América Latina post 2015: cambios en las relaciones comerciales en un contexto de menor crecimiento y reformas estructurales. En E. Dussel (coord.), América Latina y el Caribe y China. Economía, comercio e inversión 2017, (pp. 147-173) Ciudad de México: Unión de Universidades de América Latina y el Caribe..

Tang, M. (2017). El impacto del Tratado de Libre Comercio entre China y Perú en las agro exportaciones no tradicionales: el caso de la uva fresca de mesa. En E. Dussel (coord.), América Latina y el Caribe y China. Economía, comercio e inversión 2017 (pp. 175-194). Ciudad de México: Unión de Universidades de América Latina y el Caribe

Wise, C. (2016). Playing both sides of the Pacific: Latin America's Free Trade Agreements (FTAs) with China. Pacific Affairs, 89(1), 75-101. https://doi.org/10.5509/201689175

Wise, C. y Chonn Ching, V. (2018). Conceptualizing China-Latin America relations in the twenty-first century: the boom, the bust, and the aftermath. The Pacific Review, 5, 553-572. https://doi.org/10.1080/09512748.2017.1408675

Recibido: 16 de abril de 2019

Aprobado: 24 de julio de 2019 